\title{
Colorimetric Sensor Based on $\beta$-Cyclodextrin-Functionalized Silver Nanoparticles for Zidovudine Sensitive Determination
}

\author{
Farhad Ghanizadeh Gerayeli, ${ }^{1}$ Farnaz Hosseini, ${ }^{1}$ Zohreh Bagheri, ${ }^{2}$ Amir Savardashtaki, ${ }^{3}$ \\ Zahra Shabaninejad, ${ }^{4,5}$ Ali Mohammad Amani, ${ }^{1}$ and Sohrab Najafipour $\mathbb{D}^{6,7}$ \\ ${ }^{1}$ Department of Medical Nanotechnology, School of Advanced Medical Sciences and Technologies, \\ Shiraz University of Medical Sciences, Shiraz, Iran \\ ${ }^{2}$ Department of Physiology, School of Medicine, Shiraz University of Medical Sciences, Shiraz, Iran \\ ${ }^{3}$ Department of Medical Biotechnology, School of Advanced Medical Sciences and Technologies, \\ Shiraz University of Medical Sciences, Shiraz, Iran \\ ${ }^{4}$ Department of Nanotechnology, Faculty of Biological Sciences, Tarbiat Modares University, Tehran, Iran \\ ${ }^{5}$ Pharmaceutical Sciences Research Center, Shiraz University of Medical Sciences, Shiraz, Iran \\ ${ }^{6}$ Department of Microbiology, School of Medicine, Fasa University of Medical Sciences, Fasa, Iran \\ ${ }^{7}$ Non Communicable Diseases Research Center, School of Medicine, Fasa University of Medical Sciences, Fasa, Iran \\ Correspondence should be addressed to Sohrab Najafipour; sohrabnajafipour@yahoo.com
}

Received 8 January 2020; Revised 22 May 2020; Accepted 26 May 2020; Published 17 June 2020

Academic Editor: Valentina Venuti

Copyright (c) 2020 Farhad Ghanizadeh Gerayeli et al. This is an open access article distributed under the Creative Commons Attribution License, which permits unrestricted use, distribution, and reproduction in any medium, provided the original work is properly cited.

\begin{abstract}
Zidovudine (ZDV) is an antiviral drug against HIV that was approved by the FDA on March, 1987. It is a reverse transcriptase inhibitor. This type of drug stops the reproduction of DNA and decreases the amount of the virus in the patients' blood. Due to the ability of forming various molecular bonds, silver nanoparticles (AgNPs) are widely used for the detection of large range of agents, including drugs. In this study, we synthesized AgNP-modified $\beta$-cyclodextrin $(\beta$-CD) using green synthesis for the sensitive and selective zidovudine (ZDV) determination. Characterization of nanoparticles was done using different methods including infrared (IR) spectroscopy, ultraviolet-visible (UV-Vis) spectroscopy, transmission electron microscopy (TEM), and also, X-ray diffraction (XRD) patterns. The AgNP $\lambda$-max peak was at approximately $405 \mathrm{~nm}$. In the presence of ZDV, yellow solution was turned to red color, and surface plasmon absorption band was dramatically centered at $560 \mathrm{~nm}$. ZDV was determined in the range of $50-500 \mu \mathrm{M}$, and the detection limit value was obtained as $42 \mu \mathrm{M}$. The sensor was used to determine ZDV in tablets with good recovery.
\end{abstract}

\section{Introduction}

Zidovudine (ZDV), also known as 3-azido-3-deoxythymidine, is a chemical component which can be phosphorylated to ZDV triphosphate in the body. The research studies indicated that phosphorylate form could prevent HIV replication with inhibition of the reverse transcriptase as a key enzyme. Moreover, ZDV is the first approved drug for AIDS and HIV disease treatment. The chemical structure of ZDV is shown in Scheme 1 [1].

Biosensors are defined as analytical devices which can detect analytes quantitatively or semiquantitatively by using biological components such as enzymes, aptamers, and antibodies as recognition elements [2]. Several methods have been used to measure $\mathrm{ZDV}$, including electrochemical methods [3], and also, high-performance liquid chromatography (HPLC) [4], but the colorimetric method using AgNPs has not been reported for this compound yet. Because of excellent plasmon absorption properties of novel metal nanoparticles (NPs), especially gold nanoparticles (AuNPs) [5] and AgNPs [6], a variety of colorimetric sensors have been developed $[7,8]$. It is a sensor by which the detection of various analytes could be recognized with naked eyes $[8,9]$. The key point of designing a colorimetric sensor is how an 


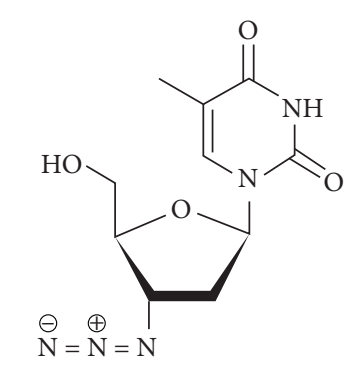

Scheme 1: Structure of ZDV.

organic compound can be used as a modifier for this metal and the author's knowledge on how to interact analytes with the sensor by considering all possibilities for interactions between a sensor and another compound. Various compounds including amino acids [10], chitosan [11], and citrate [12] have been used to repair these metals, such as gold and silver. Various compounds including amino acids [13], metal ions [10], and proteins [11] have been measured by using different types of nanoparticles of noble metal sensors. Due to unique properties including antibacterial and thermal activity, surface plasmon resonance (SPR), and catalytic and electronic properties, AgNPs have been applied remarkably in various fields [12, 14-18]. Some other materials such as chitosan [19] and cyclodextrin (CD) [20] have been used to attach silver. CDs are cyclic oligosaccharides consisting of glucopyranosyl units linked by $\alpha$ - $(1,4)$ bonds; their unique structures consist of a hydrophobic cavity and a hydrophilic surface and can form a complex structure with different groups [21]. In addition to improving solubility of insoluble compounds, CD can improve the stabilization of guests against oxidation, volatility, and sublimation, and also, mask off-flavors and control drug release to modify drug taste [22]. Due to its availability and inexpensiveness, $\beta$-cyclodextrin is available, inexpensive, and most applicable CD with $200-800 \mathrm{Da}$ molecular weight [23]. Therefore, $\beta$-cyclodextrin is used as a stabilizer for silver nanoparticles. In this research, we presented a simple, easy, and inexpensive optical chemosensor for ZDV based on silver nanoparticles.

In this research, we proposed a sensitive detection of ZDV using the AgNP SPR property. Addition of ZDV caused a diminished SPR intensity and a red shift in synthetized AgNPs. Moreover, color of AgNP solution has been changed by adding different ZDV concentrations.

\section{Materials and Methods}

2.1. Materials. We purchased silver nitrate (AgNO3) and $\beta$-cyclodextrin and Chitosan from Merck and Sigma-Aldrich, respectively. Milli-Q purified water was applied for sample preparations. After appropriate dilution, we used these solutions for the spectroscopic studies. We used hydrochloric acid $(0.1 \mathrm{M})$ and sodium hydroxide $(1.0 \mathrm{M})$ to regulate $\mathrm{pH}$.

2.2. Characterization. We recorded the UV-Vis spectra on a Unico UV-Vis spectrophotometer at $25^{\circ} \mathrm{C}$. We performed $\mathrm{pH}$ measurements by using a Denver Instrument Model $780 \mathrm{pH}$ meter equipped with a Metrohm glass electrode. TEM images were prepared with Zeiss - EM10 C - $80 \mathrm{kV}$. We obtained XRD spectra by D8 Advance type (Bruker, Germany), and Fourier-transform infrared spectroscopy (FT-IR) measurements were performed with Spectrum RX1 (Perkin Elmer, 940 Winter Street, Waltham, Massachusetts 02451, USA).

2.3. AgNP Preparation. We synthesized AgNP-functionalized $\beta$-cyclodextrin $(\beta$-CD) $(\beta$-CD-AgNPs) by a method mentioned in the literature [20]. Firstly, $20 \mathrm{~mL} \mathrm{NaOH}$ $(0.05 \mathrm{M})$ solution containing $\beta$-CD $(0.33 \mathrm{~g})$ and then $20 \mathrm{~mL}$ $\mathrm{AgNO}_{3}(0.05 \mathrm{M})$ solution were added to $60 \mathrm{~mL} \beta$-CD $(0.80 \mathrm{~g})$ aqueous solution and was stirred at $500 \mathrm{rpm}$ speed; color of solution quickly turned from colorless to light brown and became cloudy and after overnight, shifted from dark brown to transparent solution.

2.4. General Procedure for Preparation of $Z D V$. In a general procedure, under optimum conditions, we added $300.0 \mu \mathrm{L}$ of silver nanoparticle (AgNP) aqueous solution to $2.0 \mathrm{~mL} \mathrm{HCl}$ / $\mathrm{NaOH}(\mathrm{pH}=2.0)$ solution followed by adding ZDV to the reaction solution at different concentrations. Also, we recorded the probe solution absorbance at $410 \mathrm{~nm}$ and $565 \mathrm{~nm}$.

2.5. Preparation of ZDV Tablets. We performed the sample preparation steps to determine ZDV content in the produced tablets according to the reported protocol [24]. Additionally, we ground and mixed ten ZDV tablets $(150 \mathrm{mg}$ and $300 \mathrm{mg}$ per tablet) thoroughly. An adequate amount of a tablet was added in $100 \mathrm{ml}$ of distillate water and then, sonicated for 10 minutes. After filtration, $100 \mu \mathrm{L}$ of the solution was reached to $10.0 \mathrm{~mL}$ by adding $0.5 \mathrm{M} \mathrm{NaCl}$ solution. The prepared solution was used for ZDV content analysis as a real analytical sample.

\section{Results and Discussion}

3.1. $\beta-C D-A g N P$ Characterization. The synthesized AgNPs were fully characterized by TEM, XRD, FT-IR, and UV-Vis spectra. Figure 1 demonstrates the IR spectra of the AgNPs and $\beta$-CD. $\beta$-CD molecule peaks appear at 3417 and $1643 \mathrm{~cm}^{-1}$, which were related to the stretching vibration of $\beta-\mathrm{CD}-\mathrm{OH}$, the $\mathrm{C}-\mathrm{H}$ bond stretching vibration results in absorption peaks at $2912 \mathrm{~cm}^{-1}$ and $957 \mathrm{~cm}^{-1}$, and the appearance of peaks at 758,701 , and $578 \mathrm{~cm}^{-1}$ is related to the pyranose ring skeleton vibration (Figure 1(a)); the bands at $1437 \mathrm{~cm}^{-1}$ (AgNP- $\beta$-CD) and $1022 \mathrm{~cm}^{-1}$ were attributed to the bending mode of $\mathrm{CH}_{2}$ and $\mathrm{C}-\mathrm{O}$ stretching vibration, respectively $[25,26]$, and the asymmetric $\mathrm{C}-\mathrm{O}-\mathrm{C}$ stretching vibration of $\mathrm{AgNP}-\beta-\mathrm{CD}$ and $\beta$-CD was observed at $1112 \mathrm{~cm}^{-1}$ and $1109 \mathrm{~cm}^{-1}$, respectively. The spectrum of AgNP-functionalized $\beta$-CD has a strong IR absorption peak at $1658 \mathrm{~cm}^{-1}$ (Figure 1), which indicated the oxidation of hydroxyl groups during the reduction process [27]. In comparison with normal vibration wavelength, a little red shift was assigned to the $\beta$-CD coordination with the AgNP 


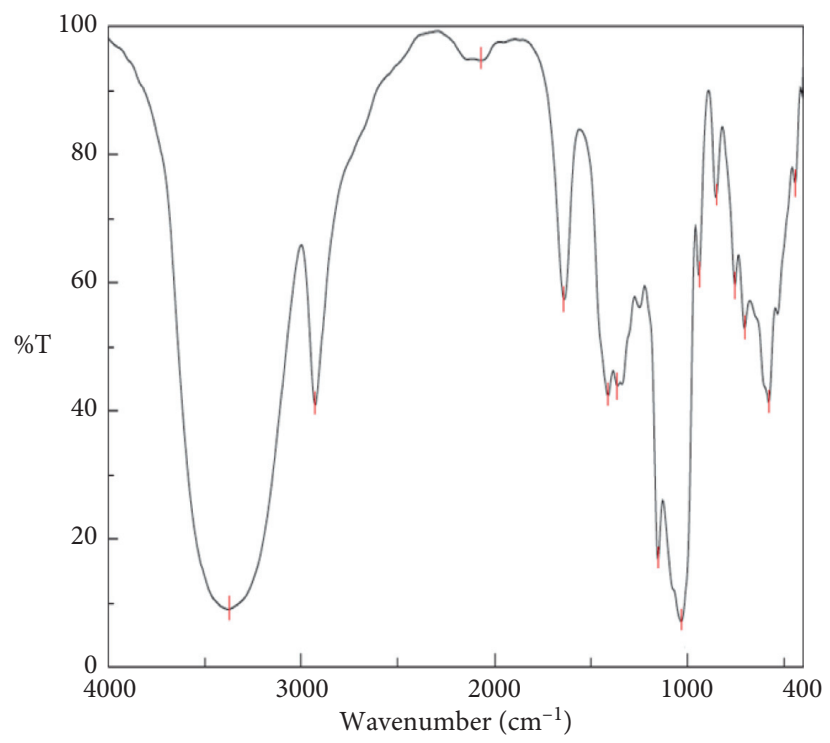

Figure 1: The FT-IR spectra of the AgNPs (a) and $\beta$-cyclodextrin.

surface [28]. TEM analysis further confirmed the formation of silver nanoparticles.

The TEM image (Figure 2) shows the uniform dispersed $\beta$-CD-AgNPs in aqueous solution with an average diameter of $25 \mathrm{~nm}$.

XRD also characterizes AgNPs were also characterized. As shown in Figure 3, the two peaks at $2 \theta$ are equal to $\sim 37.85^{\circ}$ and $\sim 43.6^{\circ}$, which are assigned to the (111) and (200) planes of the face-centered cubic (fcc) silver crystal [29]. The diffraction peaks at $29.1^{\circ}$ and $34.7^{\circ}$ can be attributed $\mathrm{AgNO}_{3}$ residuals [30].

3.2. ZDV Colorimetric Detection. The AgNP UV-Vis spectrum in the absence and presence of $\mathrm{ZDV}$ is shown in Figure 4.

In the presence of $\mathrm{ZDV}, \beta$-CD-AgNPs dramatically change color from brownish-yellow to red, which could be detected by the naked eye easily. In Scheme 2, a novel sensing approach to detect ZDV is introduced.

Based on ZDV concentration, the color and SPR intensity of AgNP solutions were changed gradually. The coordinating interaction of ZDV on the individual AgNP surface with the cavity-OH groups of $\beta$-CD might cause this shifting. CD molecules have a cavity in which hydroxyl groups are present and interact with the silver nanoparticles through hydroxyl-beta groups on the cavity and cause silver nanoparticle stability [20]. Hydroxyl groups inside a cavitation on a nanoparticle can form hydrogen bonding with other hydroxyl groups, containing hollow groups, and cause aggregation.

\subsection{Experimental Condition Optimization}

3.3.1. Effect of $p H$. Considered to evaluate optimal $\mathrm{pH}$ for detecting ZDV with $\beta$-CD-AgNPs, we utilized UV-Vis spectroscopy of $\beta$-CD-AgNPs by adding ZDV at different
$\mathrm{pH}$ ranging from 4.0 to 10.0 (Figure 5). In $\mathrm{HCl} / \mathrm{NaOH}$ solution, the maximum change $\left(A_{405} / A_{560}\right.$ : absorbance ratio changes) in the optical density was observed at $\mathrm{pH}$ 8.0. The prepared particles are unstable at $\mathrm{pH}$ below 8.0 due to loss of stability in the form of nanoparticles. Consequently, $\mathrm{pH}=8.0$ was chosen to adjust $\mathrm{ZDV} \mathrm{pH}$ solution samples.

3.3.2. Effect of AgNP Concentration. Clearly, the AgNP concentration could significantly have an effect on the sensitivity and linearity of the method. Figure 6 shows the $\beta$-CDAgNP concentration effects on UV-Vis absorption. We measured the absorbance of a series of solutions including $5.0 \times 10^{-4} \mathrm{M} Z \mathrm{ZDV}$ and various concentrations of $\beta$-CD-AgNPs in $\mathrm{HCl} / \mathrm{NaOH}$ solution $(\mathrm{pH}=8.0)$ and found the sufficient amount of AgNPs $(600.0 \mu \mathrm{l})$. Hence, $600.0 \mu \mathrm{l}$ of AgNP solution was used in further experiments.

3.3.3. Effect of Reaction Time. We investigated the incubation time effect on the absorption peak of AgNPs interacting with ZDV. As shown in Figure 7, the maximum differences of the absorption occurred after about 15.0 minutes.

3.4. Limit of Detection and Calibration Curve. Figure 8 shows the $\beta$-CD-AgNP absorption spectra changes after adding different ZDV concentrations. A linear correlation exists between $A_{405} / A_{560}$ (absorbance change ratio) and ZDV concentration over a concentration range of 50.0 to $500.0 \mu \mathrm{M}$. The calibration equation is $\Delta A=0.0084 \mathrm{C} \quad(\mu \mathrm{M})+0.9209$ $\left(R^{2}=0.9955\right)$. The detection limit of the presented design was determined from three times and found to be $42 \mu \mathrm{M}$.

3.5. Repeatability and Reproducibility. To examine repeatability and reproducibility of this method, the absorption spectra of five samples and five sensors were tested under 


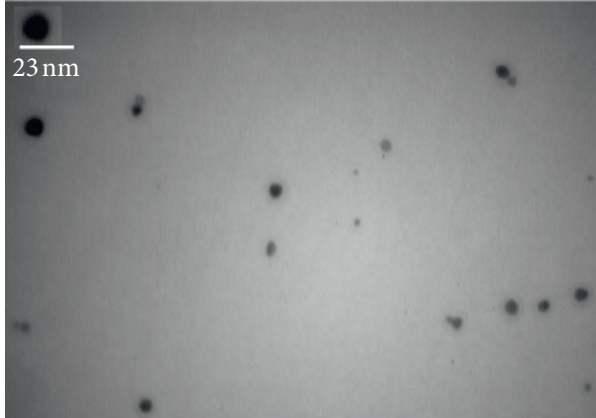

(a)

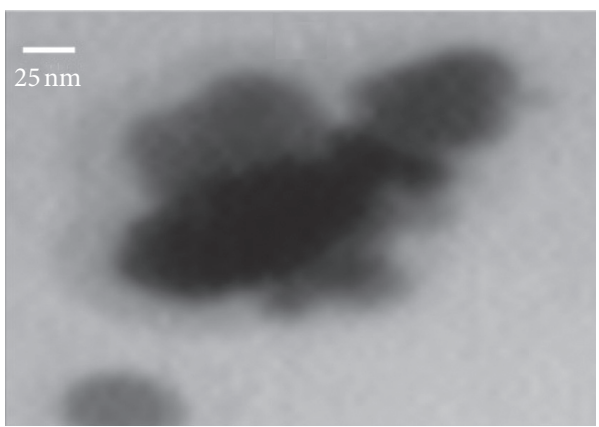

(b)

Figure 2: The TEM image analysis of the AgNPs (a) and AgNPs in the presence of zidovudine (b).

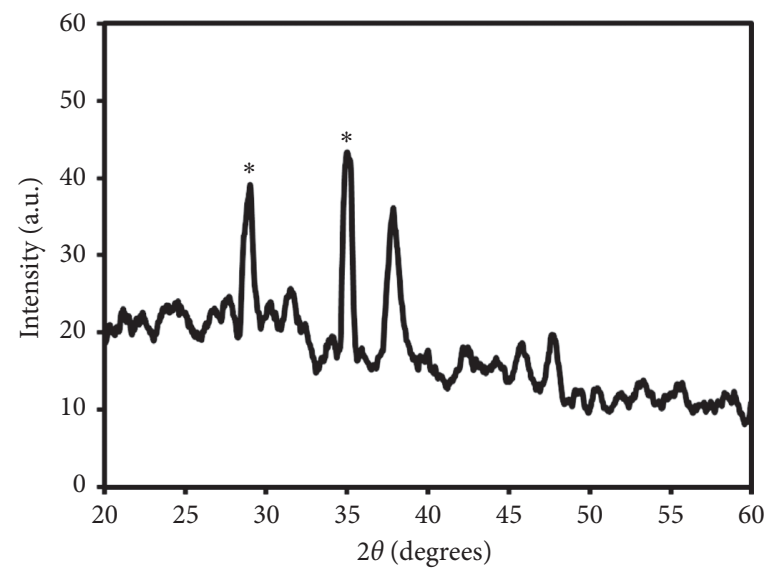

Figure 3: The XRD pattern of AgNPs. Ag metal peaks are shown with asterisk $\left(^{*}\right)$.

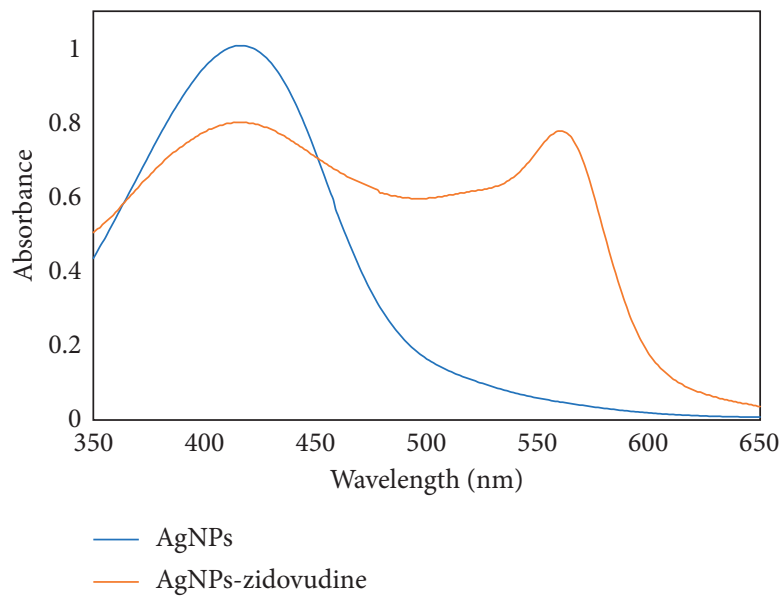

Figure 4: UV-Vis spectra of AgNPs in the absence and presence of zidovudine.

optimum conditions for $200 \mu \mathrm{M}$ of $\mathrm{ZDV}$. The relative standard deviation (RSD) for 5 measurements and 5 sensors was $3.2 \%$ and $3.6 \%$, respectively. This could indicate the desirable repeatability and reproducibility of the developed method for ZDV detection.
3.6. Real Sample Analysis. To examine the application of the proposed sensor, quantitative analysis of ZDV in its pharmaceutical products was performed under optimal conditions. According to the data (Table 1), high precision $(\mathrm{RSD} \%=1.9-3.5 \% ; N=3)$ and acceptable recovery 


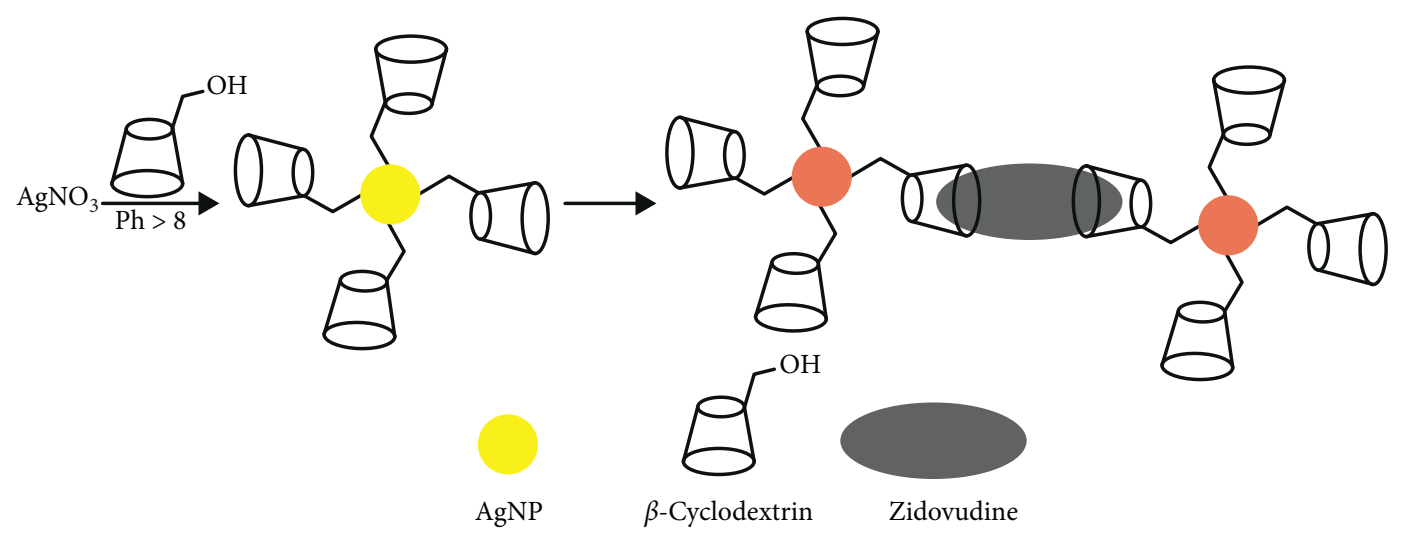

Scheme 2: Schematic diagram of calorimetric detection of zidovudine based on $\beta$-CD and its interaction with AgNPs.

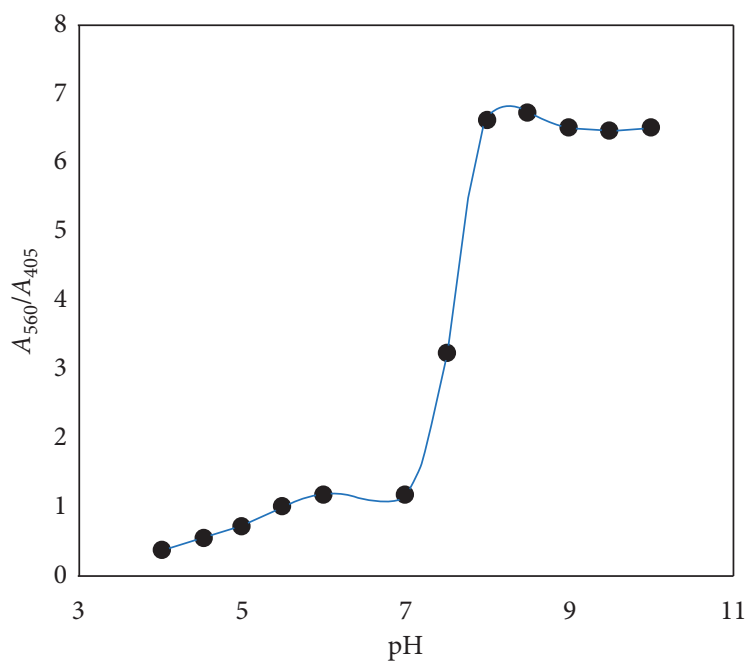

FigUre 5: UV-Vis spectra of AgNPs prepared under different $\mathrm{pH}$ values. Experimental conditions: $5.0 \times 10^{-4} \mathrm{M}$ of zidovudine, $\mathrm{pH} 4.0-10.0$ in $\mathrm{HCl} / \mathrm{NaOH}$ solution, and response time of $15 \mathrm{~min}$.

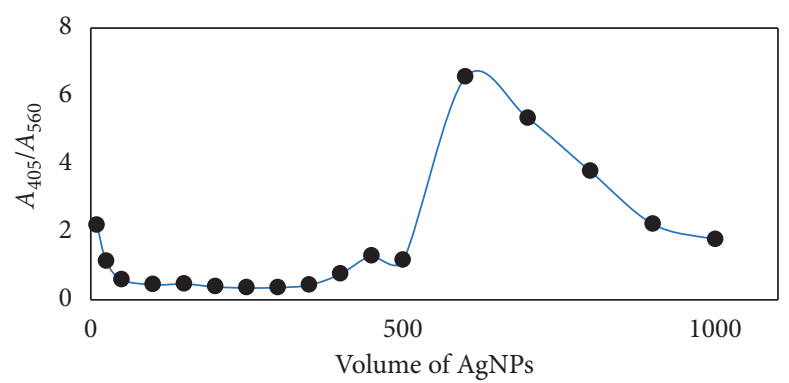

Figure 6: Effect of the volume of AgNPs on the response of the sensor; experimental conditions: $5.0 \times 10^{-4} \mathrm{M}$ of zidovudine, $\mathrm{pH} 8.0 \mathrm{in} \mathrm{HCl} /$ $\mathrm{NaOH}$ solution, and response time of $15 \mathrm{~min}$.

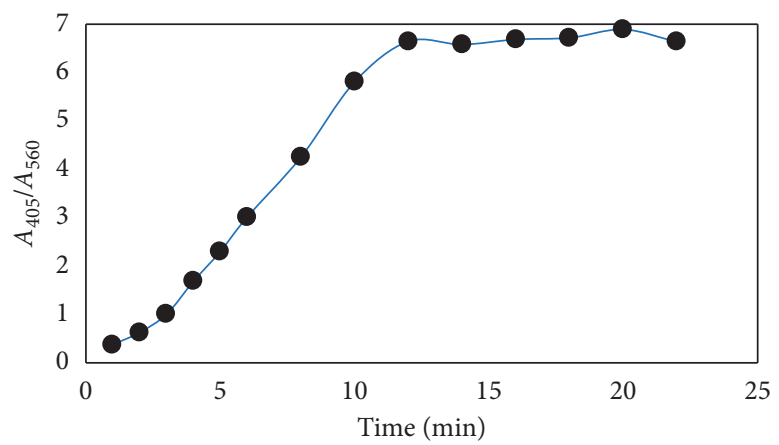

FIgURE 7: Reaction time of the colorimetric sensor for $5.0 \times 10^{-4}$ zidovudine. 


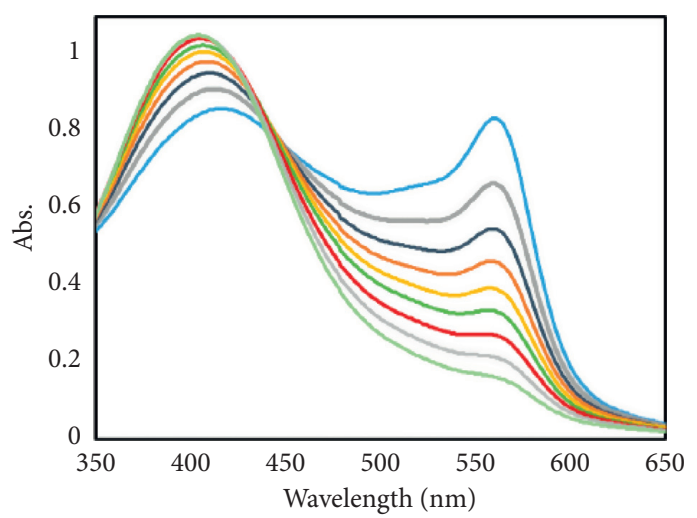

(a)

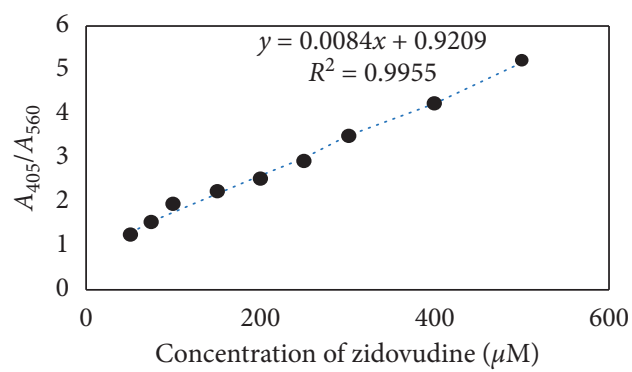

(b)

FIGURE 8: Absorbance peaks and calibration curve for AgNPs in the presence of different concentrations of zidovudine.

TABLE 1: Determination of zidovudine in the real sample using AgNPs.

\begin{tabular}{ccccc}
\hline Sample & Added $(\mu \mathrm{M})$ & Found $(\mu \mathrm{M})$ & Recovery\% & RSD\% \\
\hline \multirow{4}{*}{ Tablet } & 0 & 120 & - & 2.3 \\
& 80 & 198 & 97.5 & 1.9 \\
& 200 & 321 & 100.5 & 2.8 \\
& 400 & 523 & 100.75 & 3.5 \\
\hline
\end{tabular}

ranges (97.5-100.75\%) showed that the proposed sensor might be suggested as a reliable sensor under laboratory conditions.

\section{Conclusions}

Based on unique properties of AgNPs, such as SPR and ability to form different chemical bonds, we presented a visual colorimetric sensor based on $\beta$-CD-AgNPs for ZDV detection. This biosensor is not only facile, cost-effective and specific but also shows ideal collodial stability and sensitivity with $42 \mu \mathrm{M}$ limit of detection. The developed nano-based biosensor could successfully detect ZDV in tablet samples. Also, this approach may be usefull for other drugs and chemical agents detection.

We presented a simple, facile, low-cost and efficient, sensitive ZDV sensor based on distinct $\beta$-CD-AgNPs color change which can be distinguishing visually. The $\beta$-CDAgNPs demonstrated an ideal colloidal stability and this approach possessed a relatively good selectivity lowest detection concentration of $42 \mu \mathrm{M}$ for ZDV detection.

\section{Conflicts of Interest}

The authors declare that there are no conflicts of interest regarding the publication of this paper.

\section{Acknowledgments}

This research was supported by the Research Council of Shiraz University of Medical Sciences, Nanomedicine and
Nanobiology Research Center, and the Iran National Science Foundation (INSF).

\section{References}

[1] H. Mitsuya, R. Yarchoan, and S. Broder, "Molecular targets for AIDS therapy,” Science, vol. 249, no. 4976, pp. 1533-1544, 1990.

[2] Z. Shabaninejad, F. Yousefi, A. Movahedpour et al., "Electrochemical-based biosensors for microRNA detection: nanotechnology comes into view," Analytical Biochemistry, vol. 581, p. 113349, 2019.

[3] A. A. Rafati and A. Afraz, "Amperometric sensing of anti-HIV drug zidovudine on Ag nanofilm-multiwalled carbon nanotubes modified glassy carbon electrode," Materials Science and Engineering: C, vol. 39, pp. 105-112, 2014.

[4] A. Savaşer, S. Goraler, A. Taşöz, B. Uslu, H. Lingeman, and S. A. Özkan, "Determination of abacavir, lamivudine and zidovudine in pharmaceutical tablets, human serum and in drug dissolution studies by HPLC," Chromatographia, vol. 65, no. 5-6, pp. 259-265, 2007.

[5] P. Kumar, M. S. Ashawat, and V. Pandit, "Gold nanoparticlesmall drug molecule conjugates: therapeutic applications and benefits as compared to free drug," Asian Journal of Pharmacy and Technology, vol. 8, no. 1, pp. 52-62, 2018.

[6] D. Ahmed, M. Raza, S. Perveen, and S. Ahmed, "Cephradine coated silver nanoparticle their drug release mechanism, and antimicrobial potential against gram-positive and gramnegative bacterial strains through AFM," Journal of the Chemical Society of Pakistan, vol. 40, no. 2, 2018.

[7] Z. Zhang, H. Wang, Z. Chen, X. Wang, J. Choo, and L. Chen, "Plasmonic colorimetric sensors based on etching and growth of noble metal nanoparticles: strategies and applications," Biosensors and Bioelectronics, vol. 114, pp. 52-65, 2018.

[8] N. Sattarahmady, A. Movahedpour, H. Heli, and G. R. Hatam, "Gold nanoparticles-based biosensing of Leishmania major kDNA genome: visual and spectrophotometric detections," Sensors and Actuators B: Chemical, vol. 235, pp. 723-731, 2016.

[9] C. Karami, S. Y. Mehr, E. Deymehkar, and M. A. Taher, "Naked eye detection of $\mathrm{Cr} 3+$ and $\mathrm{Co} 2+$ ions by gold nanoparticle modified with azomethine," Plasmonics, vol. 13, no. 2, pp. 537-544, 2018.

[10] F. Sang, X. Li, Z. Zhang, J. Liu, and G. Chen, "Recyclable colorimetric sensor of $\mathrm{Cr} 3+$ and $\mathrm{Pb} 2+$ ions simultaneously 
using a zwitterionic amino acid modified gold nanoparticles," Spectrochimica Acta Part A: Molecular and Biomolecular Spectroscopy, vol. 193, pp. 109-116, 2018.

[11] C. D. Walkey, J. B. Olsen, F. Song et al., "Protein corona fingerprinting predicts the cellular interaction of gold and silver nanoparticles," ACS Nano, vol. 8, no. 3, pp. 2439-2455, 2014.

[12] S.-T. Yang, Y. Chang, H. Wang et al., "Folding/aggregation of graphene oxide and its application in Cu2+ removal," Journal of Colloid and Interface Science, vol. 351, no. 1, pp. 122-127, 2010.

[13] F. Bamdad, F. Khorram, M. Samet, K. Bamdad, M. R. Sangi, and F. Allahbakhshi, "Spectrophotometric determination of L-cysteine by using polyvinylpyrrolidone-stabilized silver nanoparticles in the presence of barium ions," Spectrochimica Acta Part A: Molecular and Biomolecular Spectroscopy, vol. 161, pp. 52-57, 2016.

[14] A. H. Alshehri, M. Jakubowska, A. Młożniak et al., "Enhanced electrical conductivity of silver nanoparticles for high frequency electronic applications," ACS Applied Materials \& Interfaces, vol. 4, no. 12, pp. 7007-7010, 2012.

[15] G. Yang, J. Xie, F. Hong, Z. Cao, and X. Yang, "Antimicrobial activity of silver nanoparticle impregnated bacterial cellulose membrane: effect of fermentation carbon sources of bacterial cellulose," Carbohydrate Polymers, vol. 87, no. 1, pp. 839-845, 2012.

[16] W. Zhao, H. Wang, X. Qin et al., "A novel nonenzymatic hydrogen peroxide sensor based on multi-wall carbon nanotube/silver nanoparticle nanohybrids modified gold electrode," Talanta, vol. 80, no. 2, pp. 1029-1033, 2009.

[17] J. Llorca, A. Casanovas, M. Domínguez et al., "Plasma-activated core-shell gold nanoparticle films with enhanced catalytic properties," Journal of Nanoparticle Research, vol. 10, no. 3, pp. 537-542, 2008.

[18] R. Karimzadeh and N. Mansour, "The effect of concentration on the thermo-optical properties of colloidal silver nanoparticles," Optics \& Laser Technology, vol. 42, no. 5, pp. 783-789, 2010.

[19] S. C. Boca, M. Potara, F. Toderas, O. Stephan, P. L. Baldeck, and S. Astilean, "Uptake and biological effects of chitosancapped gold nanoparticles on Chinese Hamster Ovary cells," Materials Science and Engineering: C, vol. 31, no. 2, pp. 184-189, 2011.

[20] P. Li, S. Li, Y. Wang, Y. Zhang, and G.-Z. Han, "Green synthesis of $\beta$-CD-functionalized monodispersed silver nanoparticles with ehanced catalytic activity," Colloids and Surfaces A: Physicochemical and Engineering Aspects, vol. 520, pp. 26-31, 2017.

[21] H.-J. Buschmann and E. Schollmeyer, "Applications of cyclodextrins in cosmetic products: a review," Journal of Cosmetic Science, vol. 53, no. 3, pp. 185-192, 2002.

[22] H. M. C. Marques, "A review on cyclodextrin encapsulation of essential oils and volatiles," Flavour and Fragrance Journal, vol. 25, no. 5, pp. 313-326, 2010.

[23] K. Waleczek, "Phase solubility studies of pure (-)- $\alpha$-bisabolol and camomile essential oil with $\beta$-cyclodextrin," European Journal of Pharmaceutics and Biopharmaceutics, vol. 55, no. 2, pp. 247-251, 2003.

[24] J. Tashkhourian, B. Hemmateenejad, H. Beigizadeh, M. Hosseini-Sarvari, and Z. Razmi, "ZnO nanoparticles and multiwalled carbon nanotubes modified carbon paste electrode for determination of naproxen using electrochemical techniques," Journal of Electroanalytical Chemistry, vol. 714715, pp. 103-108, 2014.
[25] O. Egyed, "Spectroscopic studies on $\beta$-cyclodextrin," Vibrational Spectroscopy, vol. 1, no. 2, pp. 225-227, 1990.

[26] H. -J. Schneider, F. Hacket, V. Rüdiger, and H. Ikeda, "NMR studies of cyclodextrins and cyclodextrin complexes," Chemical Reviews, vol. 98, no. 5, pp. 1775-1786, 1998.

[27] Y. Li, X. Lei, H. Dong, and T. Ren, "Sheddable, degradable, cationic micelles enabling drug and gene delivery," RSC Advances, vol. 4, no. 16, pp. 8165-8176, 1998.

[28] L. B. Devi and A. B. Mandal, "Self-assembly of Ag nanoparticles using hydroxypropyl cyclodextrin: synthesis, characterisation and application for the catalytic reduction of pnitrophenol," RSC Advances, vol. 3, no. 15, pp. 5238-5253, 2013.

[29] E. Filippo, A. Serra, and D. Manno, "Poly (vinyl alcohol) capped silver nanoparticles as localized surface plasmon resonance-based hydrogen peroxide sensor," Sensors and Actuators B: Chemical, vol. 138, no. 2, pp. 625-630, 2009.

[30] L. Prodi, "Luminescent chemosensors for transition metal ions," Coordination Chemistry Reviews, vol. 205, no. 1, pp. $59-83,2000$. 